arthritis. Similar nodules have since been recognised in patients with rheumatoid arthritis exposed to dusts in potteries, sandblasting, and iron and brass foundries, and (rarely) after exposure to asbestos. ${ }^{2}$ These nodules may precede, accompany, or follow the onset of joint symptoms; they are smaller (1-2 $\mathrm{cm}$ diameter), more generalised in distribution, and earlier in onset than progressive massive fibrosis (PMF). They may also be distinguished histologically from PMF by the presence of a layer of histiocytes surrounding the central area of necrotic collagen. The nodules may remain quiescent or heal by fibrosis. Occasionally they become infected or calcify, and rarely cavitation and rupture may cause haemoptysis or a pneumothorax. On rare occasions single or multiple lung nodules, varying in diameter from 1 to $5 \mathrm{~cm}$ or more, may develop in patients with rheumatoid arthritis without dust exposure. These are twice as common in men and are usually associated with the presence of subcutaneous rheumatoid nodules. They may undergo changes similar to the Caplan nodules.

Pleural effusions in rheumatoid disease are usually small and unilateral. They may be persistent or recurrent; and again they may precede the onset of arthritis. These effusions are up to four times more common in men than women. A clear, opalescent exudate with a low glucose content $(1.65 \mathrm{mmol} / \mathrm{l}$, $30 \mathrm{mg} / 100 \mathrm{ml}$ ) and a high lactic dehydrogenase concentration are typical findings, but occasionally the fluid may be chylous. Pleural biopsy specimens usually show non-specific fibrosis, but rarely rheumatoid nodules may be recognised. Recurring pleural effusions have also been described ${ }^{16}$ associated with intrapulmonary shadows and pericarditis.

The presence of airways obstruction in patients with rheumatoid arthritis has not attracted much comment, though cases have been recognised in most series of patients with respiratory complications of rheumatoid disease. In a recent study at least $30 \%$ of patients with normal chest radiographs and rheumatoid arthritis had airflow obstruction ${ }^{7}$; and progressive airway obliteration, mainly affecting the bronchioles, has been recognised in a number of patients. ${ }^{17}$ This latter condition, presenting as breathlessness with airflow obstruction and air trapping, was rapidly fatal in five out of six patients despite treatment. Chest films showed overinflation without pulmonary fibrosis. Acute and chronic bronchitis, bronchiectasis, and pneumonia are more frequent in patients with rheumatoid arthritis than in controls with degenerative joint disease. ${ }^{6}$ Possibly patients with rheumatoid disease may react abnormally to inflammation from various causes, tending to progress to fibrosis with damage to alveoli or airways ${ }^{1416}$; and individuals with abnormal alpha $\mathrm{a}_{1}$-antitrypsin phenotypes showing reduced tryptic-inhibitory capacity might suffer increased tissue damage and subsequent fibrosis. ${ }^{14}$ Abnormalities of $\mathrm{T}$ cell function, present in patients with rheumatoid arthritis, ${ }^{17}$ have also been cited as a possible underlying mechanism leading to impaired defences to viral infections and subsequent progressive lung damage. ${ }^{16}$ Possibly, too, respiratory infections might sometimes act as a trigger for the initiation of rheumatoid disease through inherited immunodeficiency. ${ }^{14}$

Laryngitis may be associated with damage to the cricoarytenoid joints in rheumatoid disease, when it presents with dyspnoea, stridor, and hoarseness. Rarely patients with rheumatoid arthritis may develop pulmonary hypertension caused by obliterative hypertrophy of the vascular intima of the pulmonary arteries without associated alveolar fibrosis, and affected patients often have Raynaud's phenomenon of similar aetiology.
The results of treatment of these many respiratory complications of rheumatoid disease are unrcwarding. Laryngitis may improve with corticosteroids, but tracheostomy is often necessary. Drugs may suppress pleural effusions and lung nodules, but the results of treating fibrosing alveolitis with corticosteroids in rheumatoid disease have been disappointing, and the lung changes may often accelerate after withdrawal of $\stackrel{\varrho}{c}$ these drugs. ${ }^{18}$ Treatment with compounds aimed at reducing the formation of fibrous tissue in rheumatoid disease is under evaluation.

${ }^{1}$ Ellman, P, and Ball, R E, British Medical fournal, 1948, 2, 816.

2 Scadding, J G, Proceedings of the Royal Society of Medicine, 1969, 62, 227.

${ }^{3}$ Caplan, A, Thorax, 1953, 8, 29.

${ }^{4}$ Christie, G S, Australasian Annals of Medicine, 1954, 3, 49.

${ }^{5}$ Walker, W C, and Wright, V, Annals of the Rheumatic Diseases, 1967, 26, $\overrightarrow{0}$ 467.

${ }^{6}$ Walker, W C, Quarterly fournal of Medicine, 1967, 36, 239.

${ }^{7}$ Hart, F D, British Medical fournal, 1966, 2, 131.

8 Gardner, D L, et al, Scottish Medical fournal, 1957, 2, 183. 9 Walker, W C, and Wright, V, Annals of the Rheumatic Diseases, 1969, 28,
252 .

10 Talbott, J A, and Calkins, E, Fournal of the American Medical Association, $\vec{\sigma}$ 1965, 189, 911.

11 Frank, S T, et al, Chest, 1973, 63, 27.

12 Whorwell, P J, Wojtulewski, J A, and Lacey, B W, British Medical fournal, $1975,2,175$.

13 Geddes, D M, and Brostoff, J, British Medical fournal, 1976, 1, 1444.

${ }^{14}$ Geddes, D M, et al, Lancet, 1977, 2, 1049.

${ }^{15}$ Beck, E R, and Hoffbrand, B I, Annals of the Rheumatic Diseases, 1966, 25, 459.

${ }_{16}$ Geddes, D M, et al, Quarterly fournal of Medicine, 1977, 46, 427.

${ }^{17}$ Maini, R N, et al, in Infection and Immunology in the Rheumatic Diseases, $\overparen{\mathbb{D}}$ ed D Dumonde, p 579. Oxford, Blackwell, 1976.

18 Crofton, J, and Douglas, A, Respiratory Diseases, p 626. Oxford, Blackwell, $\vec{v}$ 1975.

\section{"How long will it last, doctor?"}

Today new forms of radical treatments rarely come into general use without preliminary testing with carefully controlled clinical trials. Nevertheless, new methods of palliation, especially those that relieve pain, are not always evaluated so carefully.

A recent example is the uncritical acceptance of coronary artery bypass surgery for relieving angina pectoris. Though this $\mathrm{O}$ treatment usually cures the angina, it does nothing to the $\vec{N}$ underlying disease and prolongs the life of only a small o proportion of patients with one particular anatomical variety $\frac{D}{2}$ of coronary atherosclerosis. ${ }^{1}$ We may make precisely the same criticisms of femoropopliteal bypass surgery for intermittent claudication. This treatment has never been tested in a properly $\mathrm{C}$ conducted clinical trial; so that, while the surgeon can tell the patient that the operation, if technically successful, will cure $\frac{0}{\Phi}$ his intermittent claudication, no one knows whether it will $\stackrel{\oplus}{\leftrightarrow}$ prolong the life of his leg or how long the cure will last.

Long-term follow-up studies of patients who have had peripheral arterial surgery are difficult to arrange, largely $\stackrel{\mathbb{P}}{\stackrel{\rho}{\oplus}}$ because of the high mortality rate from coronary or cerebral $\stackrel{\mathbb{Q}}{\Omega}$ vascular disease. De Weese and Rob have recently published a careful analysis of 113 femoropopliteal vein bypass operations \& followed for 10 years. ${ }^{2}$ The most striking finding was that only 29 patients $(29 \%)$ were alive 10 years after their operation. This high mortality rate was not confined to elderly patients, for only $40^{\circ}$ of those who were between 29 and 59 years old at the time of operation were still alive.

The problem of defining success in terms of graft patency 
in the presence of such a high mortality rate is evident from the variety of methods of analysis that different workers have used. Should we compare patency at a fixed follow-up time against the number of patients operated on-or against the number of patients leaving hospital with patent grafts? Should we calculate the percentage of grafts patent at the time of death, or in those alive at the time of follow-up, ${ }^{3}$ or should we calculate accumulated patency rates from life tables from larger groups of patients with variable lengths of follow-up ? ${ }^{45}$

Using the data from their own study, De Weese and Rob ${ }^{2}$ showed that these three methods of analysis gave 10-year patency rates of $38^{\circ}{ }_{1}, 58^{\circ}$ (1) and $45^{\circ}{ }^{\prime}$, respectively. Which of these figures is closest to the truth? What do we tell our patients-in the light of the knowledge that five years after operation an individual patient is more likely to be dead than have a patent graft? Patients can be reassured by being told that about $60^{\prime \prime}$ " of grafts are patent five years after operation and $40^{\circ}$, patent 10 years after operation-ignoring the mortality rate. But we must not let our compassion for our patients become self-deceit and forget our total inability to treat atherosclerosis, or that such figures are of little value in the presence of conditions such as diabetes and hypertension, which will worsen the prognosis of the limb and the patient.

While acknowledging our inadequacies we might also spare time to marvel at the resilience of the long saphenous vein, which can be removed from its natural site, denervated and devascularised, and, placed in a foreign site such as the arterial circulation, function as an artery for 10 years or more. ${ }^{6}$ If we knew what factors governed such durability we might be able to make a good small-bore arterial prosthesis.

Murphy, M L, et al, Ner" England fournal of Medicine, 1977, 297, 621.

2 De Weese, J A, and Rob, C G, Surgery, 1977, 82, 775.

3 De Weese, J A, and Rob, C G, Annals of Surgery, 1971, 174, 346.

+ Darling, R C, and Linton, R R, American fournal of Surgery, 1972, 123,

Cutler, S J, and Ederer, F, fournal of Chronic Diseases, 1958, 8, 699.

${ }^{6}$ Szilagyi, D E, et al, Annals of Surgery, 1973, 178, 232.

\section{Sickle-cell anaemia in infancy}

Infants homozygous for sickle haemoglobin are said ${ }^{1}$ to begin to show clinical evidence of this disease only when the proportion of fetal haemoglobin in the red cells has fallen below about $35^{\circ}$, the rest being haemoglobin S. The switchover from fetal to adult haemoglobin synthesis is normally completed by about 200 days of age, ${ }^{2}$ but in homozygous sicklecell anaemia the proportion of fetal haemoglobin falls more slowly, ${ }^{3-5}$ being $34^{\circ}$, in 4-month-old babies compared with $11^{\circ}$ o in healthy infants. ${ }^{5}$ Some fetal haemoglobin persists throughout childhood in sickle-cell anaemia, but it tends slowly to decline. The amount varies; but populations and individuals with higher fetal haemoglobin concentrations have fewer irreversibly sickled cells in the circulation ${ }^{5}{ }^{6}$ and milder clinical disease. ${ }^{7-9}$ So while haemolysis does occur in babies with sickle-cell disease ${ }^{35}$ from an early stage-between the ages of 1 and 6 months their haemoglobin concentrations are 1-2 $\mathrm{g} / \mathrm{dl}$ below normal, and reticulocytosis is evident-the high proportion of fetal compared to sickle haemoglobin generally confers protection from serious symptoms.

The description by Heygi and his colleagues ${ }^{10}$ of homozygous sickle-cell disease presenting in the newborn period is therefore of great interest. A black girl born at term had haemolysis at birth, the cord haemoglobin concentration being $12.7 \mathrm{~g} \mathrm{dl}$; reticulocyte count $13.3 \%$; total bilirubin $53 \mu \mathrm{mol} 1(3 \cdot 1 \mathrm{mg} \mathrm{dl})$, direct $19 \mu \mathrm{mol} / 1(1 \cdot 1 \mathrm{mg} \mathrm{dl})$. Many sickled cells were seen on the blood smear. Studies of globin chain synthesis showed that homozygous sickle-cell disease was present, and haemoglobin electrophoresis showed $20^{\circ}{ }_{0}$ sickle and $80^{\prime \prime}$ "fetal haemoglobin-as would be expected in a homozygote of this age. Possibly $\mathrm{ABO}$ isoimmunisation might have contributed to the haemolysis, but Heygi et al thought that several features of the baby's illness and sudden death when aged 5 days were direct complications of her sickle-cell disease: the raised direct bilirubin concentration; abdominal distension; the presence of blood in gastric aspirates; and haematuria, proteinuria, and raised concentrations of urea and creatinine. Necropsy showed congestion of all organs and abundant sickled cells, especially in the brain and liver. Additional findings included haemosiderosis of the liver, spleen, kidney, and pancreas, and severe healing acute necrotising enterocolitis of the terminal ileum and ascending colon. Heygi et al $^{10}$ discussed seven reports of newborn infants with sickle-cell disease and why symptoms rarely occur so early. Their own patient's blood viscosity had been increased, perinatal hypoxia possibly having caused sickling of red cells and the resultant hyperviscosity perhaps contributing to her death.

Porter and Thurman ${ }^{11}$ reported 64 cases of sickle-cell anaemia diagnosed during the first year of life-21 within six months of birth-and described four main clinical patterns. An infection such as bronchitis or diarrhoea was the most frequent presenting symptom; next came dactylitis (the handfoot syndrome ${ }^{12}$ ); anaemic crisis; and then non-specific symptoms such as colic and irritability. Clinical examination might show enlargement of the liver and spleen, pallor, failure to thrive, abdominal distension, jaundice, or heart murmur. Ten babies died, eight within one month of diagnosis, from infection, anaemic crisis, or both. The susceptibility of children with sickle-cell anaemia to fatal infections ${ }^{13}$ may be due to splenic dysfunction, pneumococcal sepsis being a special risk, as it is in patients without a spleen. ${ }^{14}$ Anaemic crises result from hyperhaemolysis, bone marrow aplasia, splenic sequestration of red cells, or folate deficiency ${ }^{12-19}$; often associated with infections they are responsible for most deaths in early childhood.

The better-known manifestations of sickle-cell anaemia, such as painful abdominal and bone crises, splenic and bone infarcts, jaundice, recurrent pulmonary illnesses, and haematuria, tend to occur after the first year of life. ${ }^{40}$ Screening for haemoglobinopathy is technically possible in the neonatal period $^{21}$ but is practicable only in populations with, firstly, a high risk of having abnormal haemoglobins and, secondly, adequate medical and genetic counselling services to provide care, advice, and explanation to affected families. Thus in most countries diagnosis within the first year and the prevention of early deaths by prompt treatment still depend on knowledge of the clinical features of sickle-cell anaemia as it presents in young babies.

${ }^{1}$ Milner, P F, Clinics in Haematology, Abnormal Haemoglobins, 1974, 3, 289.

2 Colombo, B, et al, British fournal of Haematology, 1976, 32, 79.

${ }^{3}$ van Baelen, H, Vandepitte, J, and Eeckels, R, Annales de la Société Belge de Médecine Tropicale, 1969, 49, 157.

${ }^{4}$ Lewis, R A, Sickle States, p 64. Accra, Ghana University Press, 1970.

${ }^{5}$ Davis, L R, fournal of Clinical Pathology, 1976, 29, 898.

${ }^{6}$ Serjeant, G R, British fournal of Haematology, 1970, 19, 635.

7 Jackson, J F, Odom, J L, and Bell, W N, Fournal of the American Medical Association, 1961, 177, 867.

${ }^{8}$ Perrine, R P, et al, Lancet, 1972, 2, 1163. 